\title{
PROGNOSTIC SIGNIFICANCE OF GLUT-1 AND P-SRC EXPRESSION IN MUCOEPIDERMOID CARCINOMA
}

\author{
Nagla M. Salama* and Laila E. Amin ${ }^{* *}$
}

\begin{abstract}
Background and objective: Mucoepidermoid carcinoma (MEC) includes a variety of clinical, biological, and histological forms, all of which pose difficulties and challenges in terms of diagnosis, grading, and treatment. Glucose transporter protein 1 (GLUT-1) is involved in the glycolysis of tumor cells. This protein's high expression in malignant neoplasms is linked to tumor aggressiveness. P-Src belongs to a family of cytoplasmic tyrosine kinases and plays a role in tumor initiation and progression. The study aims to predict the aggressiveness of different grades of MEC through studying the expression of GLUT-1 and p-Src in five years of follow-up.
\end{abstract}

Materials and methods: Thirty paraffin blocks, included MEC from the pathology laboratory of the Oncology Center Mansoura University were preceded for post-operative follow-up for at least five years. Hematoxylin and eosin stained sections, tumors were scored and graded according to WHO grading system 4th edition. Disease-free survival (DFS) and overall survival (OS) were determined for each case. Immunohistochemical staining for the rabbit polyclonal antibody antiGLUT-1 and the rabbit polyclonal antibody anti p-Src were performed using a Dako Autostainer with a Universal Staining System.

Results: A statistically significant correlation between GLUT-1 and p-Src expression with tumor grades, DFS, and OS. Direct correlation between GLUT-1 and p-Src expression regarding tumor grades, the living and dead status of the cases, recurrence, DFS, and OS.

Conclusion: GLUT-1 and p-Src might serve as good prognostic markers for MEC as their expression is associated with tumor grades, DFS and OS, they might be considered promising therapeutic targets for MEC.

KEYWORDS: Mucoepidermoid carcinoma; GLUT-1; p-Src.

* Associate Professor of Oral Pathology, Faculty of Dentistry, Mansoura University; Associate Professor of Oral Pathology, Faculty of Dentistry, Horus University, Egypt.

** Associate Professor of Oral Biology, Faculty of Dentistry, Mansoura University; Associate Professor of Oral Biology, Faculty of Dentistry, Horus University, Egypt. 


\section{INTRODUCTION}

Salivary gland tumors are uncommon in humans, accounting for $5 \%$ of head and neck cancers and 0.3 percent of all cancers ${ }^{[1-3]}$. Despite their rarity, these neoplasms are heterogeneous, with at least 24 different histologic subtypes identified by the World Health Organization (WHO), each with its clinical presentation, metastasis, and recurrence [4,5]. Mucoepidermoid carcinoma (MEC) is the most frequent malignant salivary gland tumor in adults and children ${ }^{[6]}$. The parotid gland is the most common location, followed by the minor salivary glands of the lip and palate ${ }^{[7]}$. It is accounting for $10 \%-15 \%$ of all salivary gland tumors and $30 \%$ of malignant salivary gland tumors ${ }^{[8]}$. MEC is more common in women than in men, with the fifth decade of life being the most common ${ }^{[9,10]}$.

MEC stands for clinical, biological, and histological variability, which can render a diagnosis, grading, and treatment more complicated ${ }^{[11]}$. Lowgrade tumors are firm, cystic masses that are wellcircumscribed and unencapsulated or partially encapsulated under the microscope. Patients describe a painless swelling that grows slowly. On the other hand, high-grade tumors are solid, poorly defined masses with infiltrative boundaries fixed to surrounding tissues. Exclusively, in parotid gland tumors patients typically describe a rapidly developing painful swelling caused by facial nerve involvement ${ }^{[12]}$.

According to WHO classification, MECs are categorized into three histopathologic grades; low, intermediate, and high grade based on relative numbers of mucous, intermediate, and epidermoid cells ${ }^{[4,5]}$. Cut sections may reveal solid and cystic parts; cystic gaps commonly contain mucinous or hemorrhagic material, whereas solid portions are grayish-white or brown in appearance [13]. Epidermoid/squamous cells are polygonal in shape, with abundant eosinophilic cytoplasm and ovoid, vesicular nuclei under the microscope. They create solid nests with intercellular bridging, and individual cell keratinization is uncommon. Mucous cells are found in low-grade malignancies and feature pale to mildly basophilic cytoplasm with compressed nuclei. If mucous secretions leak into surrounding tissues, mucin pools and a foreign body giant-cell reaction may develop. Intermediate cells vary in size and feature a tiny, centrally placed nucleus with little cytoplasm ${ }^{[13,14]}$.

Low-grade tumors frequently have well-differentiated glandular or cystic features and are lined by a single layer of mucous-secreting cells. Intermediate-grade tumors include small cystic gaps lined by primarily columnar cells with surrounding solid sections of intermediate and epidermoid cells. There may also be papillary cystic infoldings, focal invasion, mild cellular pleomorphism, and mitotic figures. In high-grade tumors, typical solid nests or sheets of cells are made mostly of epidermoid cells with a minor cystic component. They also show signs of invasion, necrosis, cellular pleomorphism, and a higher number of mitoses ${ }^{[14,15]}$. Low-grade tumors, especially those in the early stage, and nodalfree have a good prognosis ${ }^{[16]}$.

High-grade and nodal metastasis, on the other hand, have a worse survival rate. Survival and prognosis have been linked to clinical stages and histological grades ${ }^{[6]}$. The predictive variables associated with MEC have not been adequately studied until now ${ }^{[7]}$. Several studies have failed to improve the tumor's prognostic criteria significantly ${ }^{[17]}$. As a result, more research on the MEC is critical to developing improved prognostic predictions and appropriate treatment regimens ${ }^{[18]}$.

Glycolysis, commonly known as the Warburg effect ${ }^{[19,20]}$, has been identified as an important marker of human cancer. Several glycolytic genes, including pyruvate kinase isozyme M2 (PKM2), lactate dehydrogenase A (LDHA), hexokinase 2 (HK2), and glucose transporter (GLUT), are highly expressed in malignant tumors and have been associated with tumor aggressiveness ${ }^{[21,22]}$. GLUT- 
1, one of the glucose transporters (GLUT) proteins, is the primary glucose transporter found in all cells of various tissues and organs. This protein regulates glucose entry into cells and maintains homeostasis, which is necessary for the organism's vital functions. In physiological conditions, increased metabolic demand causes GLUT-1 expression levels to rise. GLUT-1, on the other hand, has a role in tumor cell glycolysis under pathological situations ${ }^{[23-25]}$.

In various malignant neoplasms, increased expression of this protein is linked to tumor invasion, aggressiveness ${ }^{[23,24]}$, metastasis, and a low survival rate ${ }^{[26-28]}$. By enhancing tumor cell glycolysis, GLUT-1 overexpression provides energy for cells to spread to distant metastasis, as a result, inhibiting the function of GLUT-1 could prevent tumor cells from invading and migrating ${ }^{[29-31]}$.

Src is a cytoplasmic tyrosine kinase involved in the initiation and progression of tumors ${ }^{[32]}$. Multiple signaling pathways can activate Src to become phospho-Src (p-Src), and it can phosphorylate target proteins to activate specific signaling pathways ${ }^{[33]}$. Src and intracellular signaling pathways thus play an essential role in regulating vital cellular processes like cell morphology, differentiation, adhesion, migration, invasion, proliferation, and survival ${ }^{[34]}$. In recent research, Src family kinases have been discovered to mediate a range of cancers ${ }^{[35]}$, and their activation has been linked to a more aggressive neoplastic phenotype ${ }^{[34]}$. Phosphorylated Src enhances epithelial cell mechanical alterations such as migration, transformation, and invasion, others, strengthen the relationship between Src activation and tumor progression ${ }^{[35,36]}$.

Overexpression or activation of Src protein has been documented in various human malignancies, including breast, pancreatic, and colorectal can$\operatorname{cer}^{[36]}$, and is frequently associated with poor clinical outcomes ${ }^{[37]}$. Src and p-Src expression were also high in other malignant tumors like squamous cell carcinoma of the tongue, rhabdomyosarcoma, and Ewing's sarcoma. This high expression was positively correlated with metastasis and clinical stage but negatively correlated with post-operative survival ${ }^{[33]}$. Although the molecular processes by which cancer cells retain and cope with high levels of promiscuous activated tyrosine kinases like Src are unexplained ${ }^{[37]}$, further research is needed to validate $\mathrm{p}$-Src's function in tumor formation and progression ${ }^{[36]}$.

The study aims to predict the aggressiveness of different grades of MEC through studying the expression of GLUT-1 and p-Src in five years of follow-up.

\section{MATERIALS AND METHODS}

This study was performed retrospectively, patients diagnosed with MEC who had radical surgeries between the years 2015 and 2020 at Oncology Center, Mansoura University (OCMU), Egypt, and proceeded for post-operative follow-up for at least five years, after exclusion of cases with insufficient material, only thirty patients met these criteria. Paraffin-embedded specimens retrieved from the pathology laboratory of the (OCMU) were enrolled. Clinical, demographic, and follow-up data were collected from patient reports.

Paraffin-embedded tissue was sliced into $4 \mu \mathrm{m}$ thickness. Hematoxylin and eosin (H\&E) stained sections from MEC were examined, and tumors were scored and graded according to the WHO grading system $4^{\text {th }}$ edition, $2017^{(5)}$. This system sets up three grades of malignancy: low grade (twelve cases), intermediate grade (ten cases), and high grade (eight cases), based on the overall extent of tumor cells. As a control group, six normal salivary tissues from mucocele cases were retrieved from the Oral Pathology Department, faculty of dentistry, Mansoura University, Egypt. From each block, 4 $\mu \mathrm{m}$ thickness was cut and mounted on glass slides previously prepared with an organosilane-based adhesive (3-aminopropyl) triethoxysilane, Sigma Chemical Co®, St Louis, MO, USA). 
Disease relapse-free patients or disease-free survival (DFS) was computed from diagnosis until the first incidence of local recurrence or metastasis or last contact at the end of the study period. The time from diagnosis to death or last contact was referred to as overall survival (OS). The DFS and OS for each case were determined.

Immunohistochemical staining for the rabbit polyclonal antibody anti-GLUT-1 (GTX15309, GeneTex ${ }^{\circledR}$, San Antonio, TX, USA) 1:200 concentration and the rabbit polyclonal antibody anti p-Src (Tyr527) (Cell Signaling Technologies, Danvers, USA), 1:100 concentration. Dakocytomation, Carpinteria, CA, USA, provided a Dako Autostainer with a Universal Staining System, and a ChemMate $^{\text {TM }}$ DAKO EnVision ${ }^{\text {TM }}$ detection kit. The evaluation and scoring of the marker in the studied samples consisted of the cells that exhibited brown staining in their cytoplasm and cell membrane. Sections of lung carcinoma and colon carcinoma were used as a positive control for GLUT-1 and p-Src respectively. Negative control sections were incubated without the primary antibody.

\section{Evaluation of immunohistochemistry}

The scoring of distribution and intensity of the stain was evaluated as follows: The distribution of stain was evaluated semi-quantitatively by two observers (both authors) according to the percentage of positively stained tumor cells in at least five areas of hot spots at high power fields (x 400) magnification and assigned to one of the following categories: $1=<25 \%, 2=25-75 \%$, and $3=>75 \%$. The percentages of tumor epithelial cells stained were graded with the exclusion of nonspecific stromal cells reaction. The staining intensity was scored as 0 indicating no staining, 1 indicating mild staining (faintly cytoplasmic reaction visible only using a higher magnification $\mathrm{x} 400$ ), 2 indicating moderate staining (cytoplasmic reaction visible only using a magnification x 100), and 3 indicating strong staining (densely stained reaction visible at low magnification $\mathrm{x} 40$ ). By multiplying the presence intensity score by the scoring of distribution; the total score for each case was computed. Negative $=0$, weak positive $=1$ to 4 , or strongly positive $=>4$ were used to categorize the total scores ${ }^{[31]}$. Positive and negative control slides were included in each reaction. Six samples of normal salivary gland tissue were taken from patients with mucocele and immunohistochemically analyzed as a control group, the same evaluation criteria of markers expression in tumor cells were applied in the control group.

\section{RESULTS}

This study was done on thirty cases of MEC with different pathological grades; six cases of normal salivary tissue obtained from mucocele, GLUT-1, and $\mathrm{p}$-Src expression were evaluated in different cases.

\section{Regarding age, site, gender, and tumor grades of studied MEC cases}

The age of the studied cases ranged from 41 to 70 years, with mean and standard deviation were (SD) 56.4 \pm 9.7 . The most prevalent site was the palate, nearly one-third of the cases (10 cases 33\%), and the submandibular area was the least 3 cases $10 \%$. Females were affected more than males; 16 $(53 \%)$ cases were females versus $14(47 \%)$ males. According to WHO classification, Low grade existed in 12 cases (40\%), intermediate grade in 10 cases $(33.3 \%)$, and high grade in 8 cases $(26.7 \%)$ (Fig.1) (Table I).

\section{Immunohistochemical results}

GLUT-1 immunoreaction was observed as brown staining throughout the cytoplasm and/or cell membrane of the tumor cells. The erythrocytes had brown staining and were considered an internal positive control. The expression was noticed in 20 cases $(67 \%)$, the reaction was patchy in low grade, and intermediate grade (Fig. 2,3), the highest expression existed in high-grade tumors (Fig.4). weak GLUT-1 expression in normal salivary 


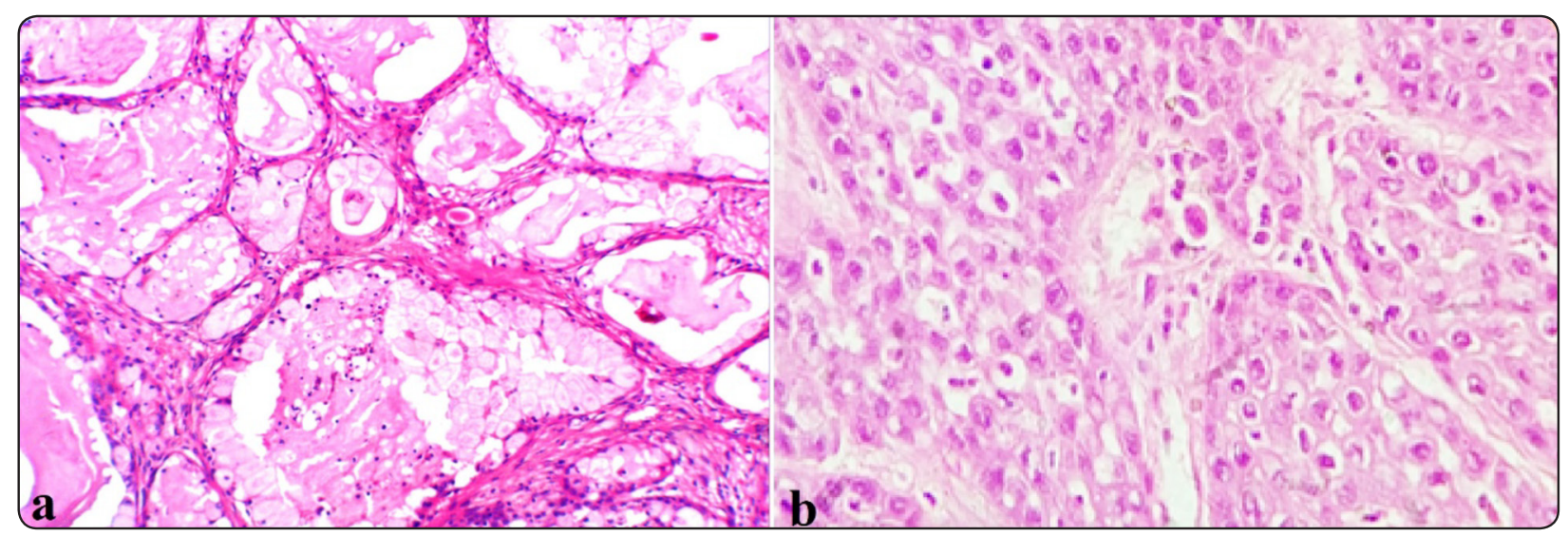

Fig. (1): Photomicrograph showing (a) low-grade mucoepidermoid carcinoma with numerous cystic spaces and mucous cells. (b) high grade with minimal cystic spaces. (x 200)

tissue adjacent to tumor cells was observed in acini; moreover, normal salivary tissue from mucocele revealed a negative reaction for GLUT1 (Fig.5). Regarding low-grade MEC, the staining distribution was negative in seven cases $(70 \%)$ and low expression in five cases $(45.5 \%)$, moreover, intermediate grade MEC revealed; negative expression in three cases (30\%), low expression in five cases $(45.5 \%)$ and high expression in two cases $(22.2 \%)$. Meanwhile, all cases of high-grade MEC were positive, statistically highly significant $(\mathrm{P}=0.001)$, the staining distribution was low expression in one case $(9.1 \%)$, and high expression in seven cases $(77.8 \%)$. There were statistically significant correlations $(\mathrm{P}=0.001)$ between the marker GLUT-1 expression and tumor grades, DFS, and OS (Tables II, III, and IV).
TABLE (I): Age, gender, site, and tumor grades of the studied cases:

\begin{tabular}{lll}
\hline Age & 41 to 70 years & $56.4 \pm 9.7$ \\
\hline \multirow{2}{*}{ Gender } & Male & $14(46.7 \%)$ \\
\cline { 2 - 3 } & Female & $16(53.3 \%)$ \\
\hline \multirow{3}{*}{ Site } & Buccal mucosa & $4(13.3 \%)$ \\
\cline { 2 - 3 } & Palate & $10(33.3 \%)$ \\
\cline { 2 - 3 } & Parotid & $9(30.0 \%)$ \\
\cline { 2 - 3 } & Retromolar area & $4(13.3 \%)$ \\
\cline { 2 - 3 } & Submandibular & $3(10.0 \%)$ \\
\hline \multirow{3}{*}{$\begin{array}{l}\text { MEC } \\
\text { grade }\end{array}$} & low & $12(40.0 \%)$ \\
\cline { 2 - 3 } & intermediate & $10(33.3 \%)$ \\
\cline { 2 - 3 } & high & $8(26.7 \%)$ \\
\hline
\end{tabular}

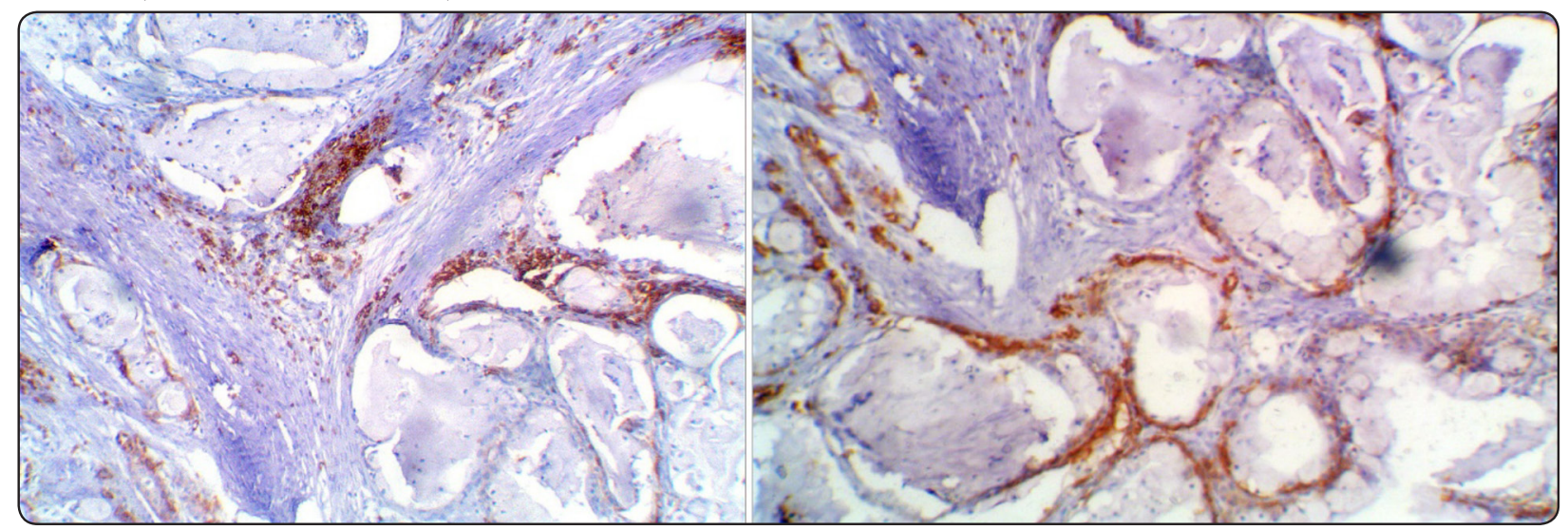

Fig. (2): Photomicrographs of low-grade mucoepidermoid carcinoma with numerous cystic spaces revealed patchy and low GLUT1 expression in between the cystic spaces. (x 100) 


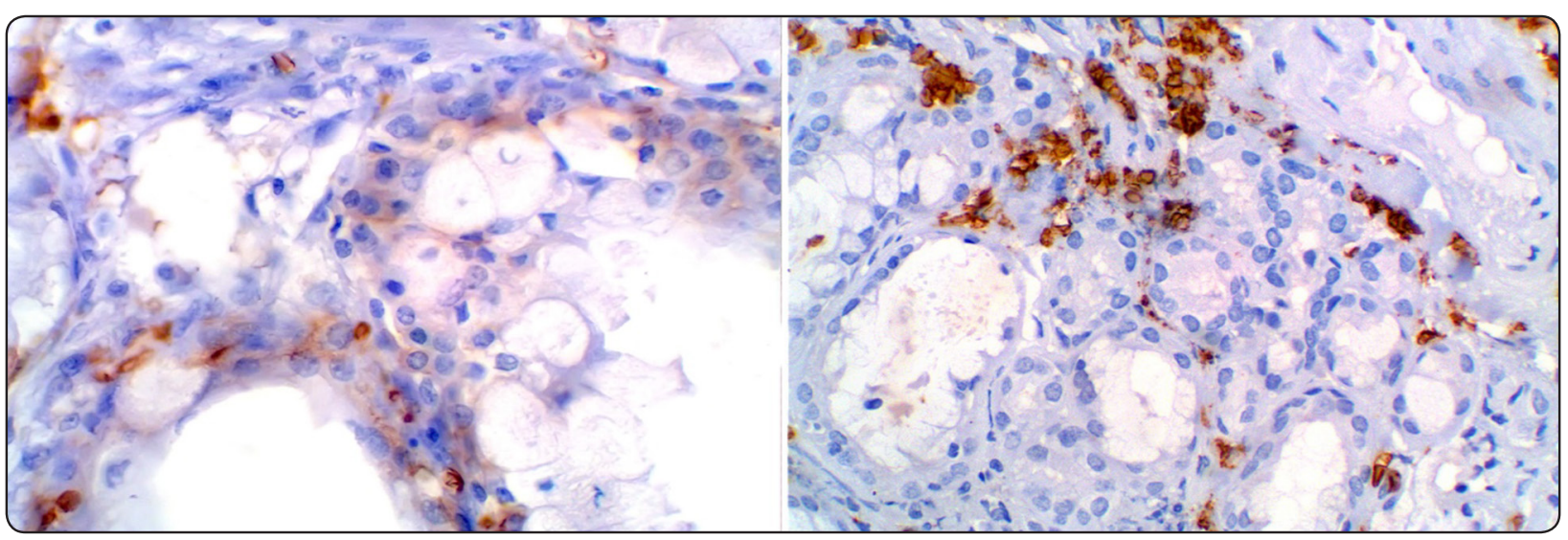

Fig. (3): Photomicrographs of intermediate grade mucoepidermoid carcinoma revealed patchy and low GLUT-1 expression. (x 200)

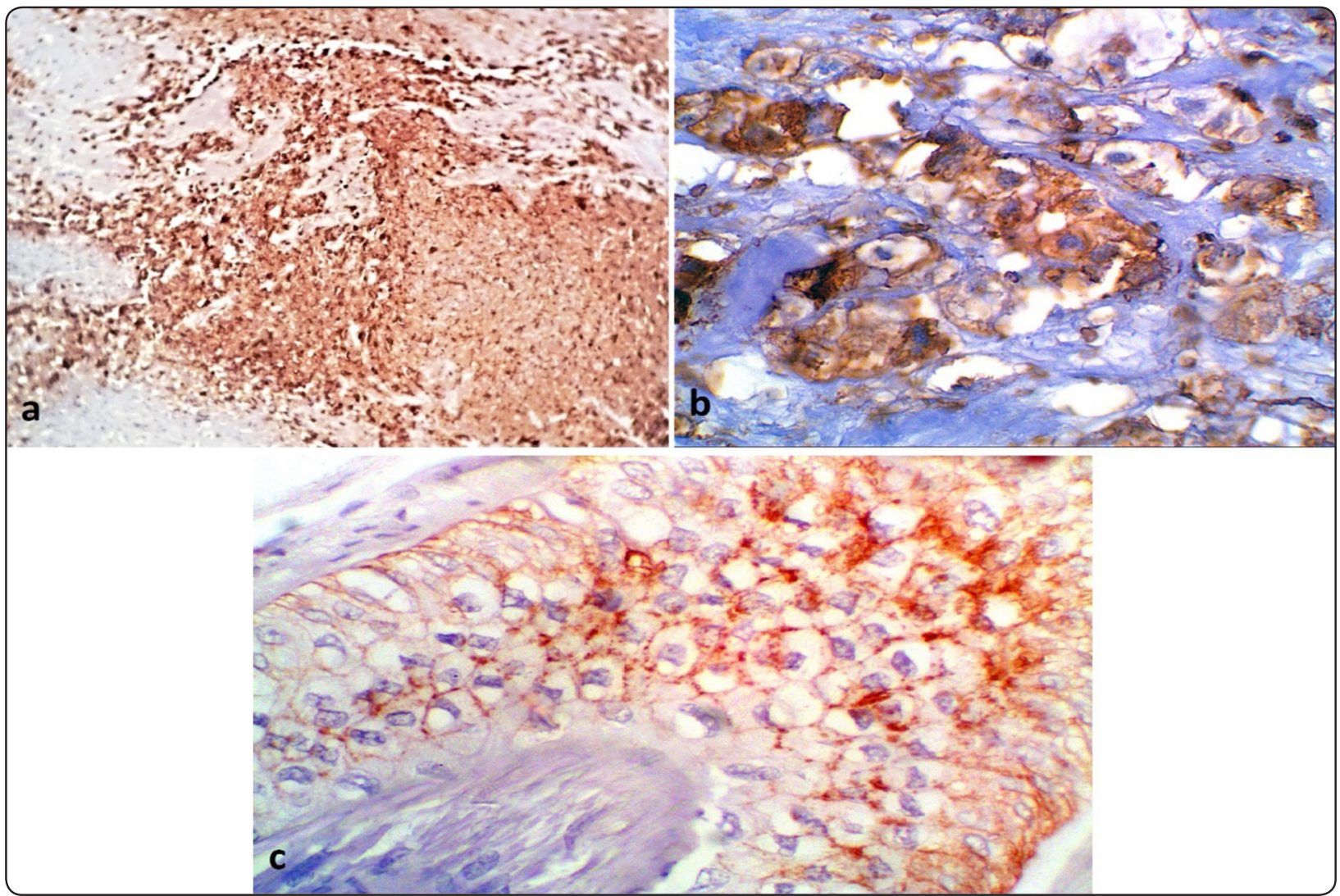

Fig. (4): Photomicrograph Of GLUT-1 expression in high-grade mucoepidermoid carcinoma revealed (a) epidermoid cells without cystic spaces and high expression (b) cytoplasmic expression in epidermoid cells. (c) clear cells and membranous expression (x 40, x 400 and x 200 respectively). 


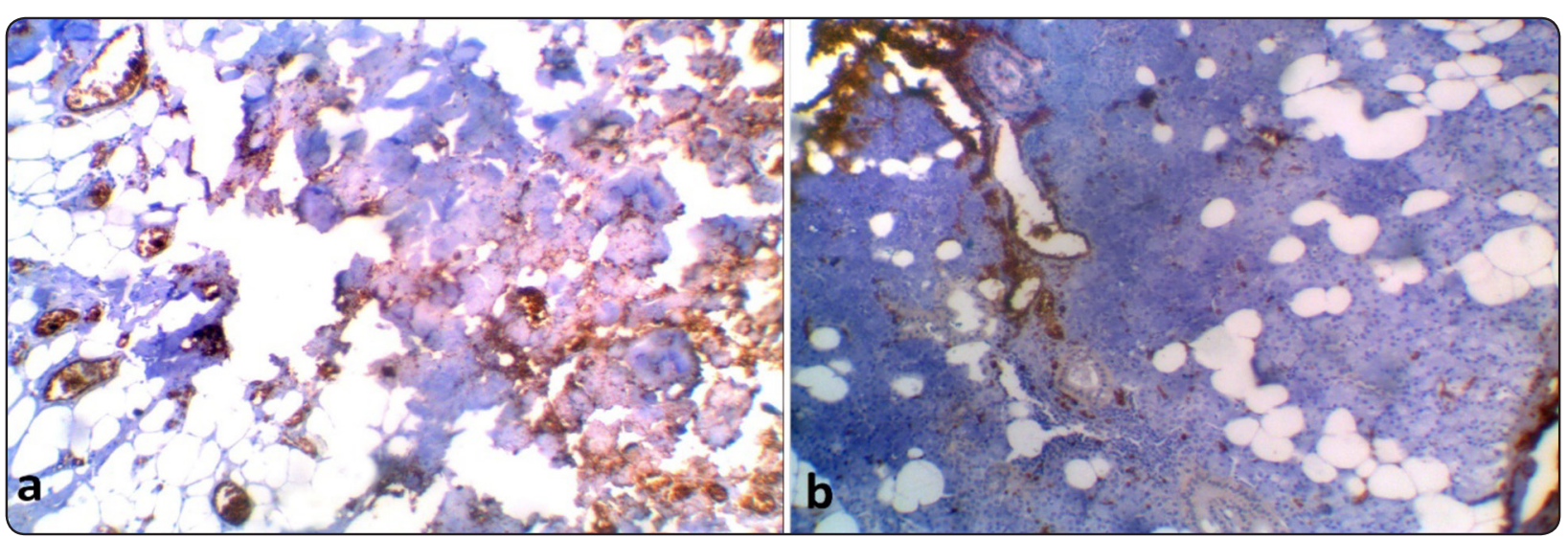

Fig. (5): Photomicrograph showing (a) salivary tissue adjacent to the tumor showing positive GLUT 1 expression in acinar cells and blood capillaries which is considered as the internal positive control, (b) normal salivary tissue from mucocele noted vascular reaction only and negative GLUT-1 expression. (x 200)

TABLE (II): GLUT-I expression concerning clinicopathological parameters:

\begin{tabular}{|c|c|c|c|c|c|c|c|c|}
\hline & & \multicolumn{6}{|c|}{ Glut 1} & \multirow[t]{2}{*}{$\mathrm{P}$} \\
\hline & & \multicolumn{2}{|c|}{ negative expression } & \multicolumn{2}{|c|}{ low expression } & \multicolumn{2}{|c|}{ high expression } & \\
\hline \multicolumn{2}{|l|}{ Age } & \multicolumn{2}{|c|}{$53.9 \pm 10.0$} & \multicolumn{2}{|c|}{$57.0 \pm 10.0$} & \multicolumn{2}{|c|}{$57.1 \pm 9.7$} & 0.7 \\
\hline \multirow{2}{*}{ Gender } & Male & 5 & $50.0 \%$ & 5 & $45.5 \%$ & 4 & $44.4 \%$ & 1.00 \\
\hline & Female & 5 & $50.0 \%$ & 6 & $54.5 \%$ & 5 & $55.6 \%$ & \\
\hline \multirow{5}{*}{ Site } & Buccal mucosa & 3 & $30.0 \%$ & 1 & $9.1 \%$ & 0 & $0.0 \%$ & 0.93 \\
\hline & Palate & 2 & $20.0 \%$ & 5 & $45.5 \%$ & 3 & $33.3 \%$ & \\
\hline & Parotid & 3 & $30.0 \%$ & 3 & $27.3 \%$ & 3 & $33.3 \%$ & \\
\hline & Retromolar area & 1 & $10.0 \%$ & 1 & $9.1 \%$ & 2 & $22.2 \%$ & \\
\hline & Submandibular & 1 & $10.0 \%$ & 1 & $9.1 \%$ & 1 & $11.1 \%$ & \\
\hline \multirow{3}{*}{ MEC grade } & low & 7 & $70.0 \%$ & 5 & $45.5 \%$ & 0 & $0.0 \%$ & $<0.001 *$ \\
\hline & intermediate & 3 & $30.0 \%$ & 5 & $45.5 \%$ & 2 & $22.2 \%$ & \\
\hline & high & 0 & $0.0 \%$ & 1 & $9.1 \%$ & 7 & $77.8 \%$ & \\
\hline \multirow{2}{*}{ Alive/ dead } & alive & 10 & $100.0 \%$ & 8 & $72.7 \%$ & 7 & $77.8 \%$ & 0.56 \\
\hline & dead & 0 & $0.0 \%$ & 3 & $27.3 \%$ & 2 & $22.2 \%$ & \\
\hline \multirow{2}{*}{ Recurrence } & No & 8 & $80.0 \%$ & 8 & $72.7 \%$ & 3 & $33.3 \%$ & 0.26 \\
\hline & Yes & 2 & $20.0 \%$ & 3 & $27.3 \%$ & 6 & $66.7 \%$ & \\
\hline DFS & & \multicolumn{2}{|c|}{$44.3 \pm 7.1^{b}$} & \multicolumn{2}{|c|}{$38.8 \pm 4.1^{b}$} & \multicolumn{2}{|c|}{$21.9 \pm 5.0^{\mathrm{a}}$} & $<0.001 *$ \\
\hline OS & & \multicolumn{2}{|c|}{$47.0 \pm 1.5^{b}$} & \multicolumn{2}{|c|}{$46.3 \pm 2.0^{\mathrm{b}}$} & \multicolumn{2}{|c|}{$37.8 \pm 4.7^{\mathrm{a}}$} & $<0.001 *$ \\
\hline
\end{tabular}

Data expressed as mean $\pm S D$

SD: standard deviation

\section{P: Probability}

* Indicate significance in mean $(P \leq 0.05)$ 
TABLE (III): GLUT-1 expression concerning DFS:

\begin{tabular}{|c|c|c|c|c|}
\hline \multirow[t]{3}{*}{ Glut 1} & \multicolumn{4}{|c|}{ Mean $^{\mathrm{a}}$} \\
\hline & \multirow[t]{2}{*}{ Estimate } & \multirow[t]{2}{*}{ Std. Error } & \multicolumn{2}{|c|}{ 95\% Confidence Interval } \\
\hline & & & Lower Bound & Upper Bound \\
\hline negative expression & 54.525 & 2.701 & 49.231 & 59.819 \\
\hline low expression & 42.100 & 1.413 & 39.330 & 44.870 \\
\hline high expression & 24.208 & 2.239 & 19.820 & 28.597 \\
\hline \multirow[t]{2}{*}{ Overall } & 45.919 & 3.052 & 39.936 & 51.901 \\
\hline & & & Chi-Square & $\mathrm{P}$ \\
\hline \multirow{3}{*}{ Log Rank (Mantel-Cox) } & \multicolumn{2}{|c|}{ Negative expression \& low expression } & 1.560 & .212 \\
\hline & \multicolumn{2}{|c|}{ Negative expression $\&$ high expression } & 16.322 & $<0.001^{*}$ \\
\hline & \multicolumn{2}{|c|}{ Low expression \& high expression } & 17.732 & $<0.001 *$ \\
\hline
\end{tabular}

P: Probability *: significance $\leq 0.05$

TABLE (IV): GLUT-1 expression concerning OS:

\begin{tabular}{llcc}
\hline & & Chi-Square & P \\
\hline Log Rank (Mantel-Cox) & negative expression \& low expression & 5.786 & $.016^{*}$ \\
\cline { 2 - 4 } & negative expression \& high expression & 4.390 & $.036^{*}$ \\
\cline { 2 - 4 } & low expression \& high expression & 4.805 & $.028^{*}$ \\
\hline
\end{tabular}

\section{P: Probability *: significance $\leq \mathbf{0 . 0 5}$}

P-Src was observed in 21 cases (70\%), and it was expressed in the cytoplasm and/or cell membrane of the tumor cells. High expression was observed in 11 cases, while low expression was detected in 10 cases. Regarding low-grade MEC, the staining distribution was negative in seven cases $(77.8 \%)$ and low expression in five cases (50\%), moreover, intermediate grade MEC revealed; negative expression in two cases (22.2\%), low expression in five cases $(50 \%)$ and high expression in three cases $(27.3 \%)$. Meanwhile, all cases of high-grade MEC (eight cases) were highly positive expression, statistically highly significant $(\mathrm{P}=0.001)$. Therefore, high-grade MEC expressed higher expression of p-Src than low and intermediate ones (Fig.6,7). Normal salivary tissue from mucocele revealed a negative reaction for $\mathrm{p}-\mathrm{Src}$. There were statistically significant correlations $(\mathrm{P}=0.001)$ between the marker expression and tumor grades, DFS, and OS (Tables V, VI, and VII). 
TABLE (V): P-Src expression concerning clinicopathological parameters:

\begin{tabular}{|c|c|c|c|c|c|c|c|c|}
\hline & & \multicolumn{6}{|c|}{$\mathrm{p}-\mathrm{Src}$} & \multirow{2}{*}{$\mathrm{P}$} \\
\hline & & \multicolumn{2}{|c|}{ negative expression } & \multicolumn{2}{|c|}{ low expression } & \multicolumn{2}{|c|}{ high expression } & \\
\hline \multicolumn{2}{|l|}{ Age } & \multicolumn{2}{|c|}{$54.3 \pm 9.8$} & \multicolumn{2}{|c|}{$57.1 \pm 10.6$} & \multicolumn{2}{|c|}{$56.4 \pm 9.6$} & 0.82 \\
\hline \multirow{2}{*}{ Gender } & Male & 5 & $55.6 \%$ & 5 & $50.0 \%$ & 4 & $36.4 \%$ & \multirow{2}{*}{0.63} \\
\hline & Female & 4 & $44.4 \%$ & 5 & $50.0 \%$ & 7 & $63.6 \%$ & \\
\hline \multirow{5}{*}{ Site } & Buccal mucosa & 4 & $44.4 \%$ & 0 & $0.0 \%$ & 0 & $0.0 \%$ & \multirow{5}{*}{0.23} \\
\hline & Palate & 2 & $22.2 \%$ & 4 & $40.0 \%$ & 4 & $36.4 \%$ & \\
\hline & Parotid & 2 & $22.2 \%$ & 3 & $30.0 \%$ & 4 & $36.4 \%$ & \\
\hline & Retromolar area & 0 & $0.0 \%$ & 2 & $20.0 \%$ & 2 & $18.2 \%$ & \\
\hline & Submandibular & 1 & $11.1 \%$ & 1 & $10.0 \%$ & 1 & $9.1 \%$ & \\
\hline \multirow{3}{*}{ MEC grade } & low & 7 & $77.8 \%$ & 5 & $50.0 \%$ & 0 & $0.0 \%$ & \multirow{3}{*}{$<0.001^{*}$} \\
\hline & intermediate & 2 & $22.2 \%$ & 5 & $50.0 \%$ & 3 & $27.3 \%$ & \\
\hline & high & 0 & $0.0 \%$ & 0 & $0.0 \%$ & 8 & $72.7 \%$ & \\
\hline \multirow{2}{*}{ Alive/ dead } & alive & 9 & $100.0 \%$ & 9 & $90.0 \%$ & 7 & $63.6 \%$ & \multirow{2}{*}{0.16} \\
\hline & dead & 0 & $0.0 \%$ & 1 & $10.0 \%$ & 4 & $36.4 \%$ & \\
\hline \multirow{2}{*}{ recurrence } & No & 7 & $77.8 \%$ & 8 & $80.0 \%$ & 4 & $36.4 \%$ & \multirow{2}{*}{0.1} \\
\hline & Yes & 2 & $22.2 \%$ & 2 & $20.0 \%$ & 7 & $63.6 \%$ & \\
\hline DFS & & \multicolumn{2}{|c|}{$43.7 \pm 7.8^{b}$} & \multicolumn{2}{|c|}{$40.3 \pm 4.5^{b}$} & \multicolumn{2}{|c|}{$24.6 \pm 7.7^{\mathrm{a}}$} & $<0.001 *$ \\
\hline OS & & \multicolumn{2}{|c|}{$46.6 \pm 2.1^{\mathrm{b}}$} & \multicolumn{2}{|c|}{$46.4 \pm 1.6^{b}$} & \multicolumn{2}{|c|}{$39.6 \pm 5.9^{a}$} & $<0.001 *$ \\
\hline
\end{tabular}

Data expressed as mean $\pm S D$

SD: standard deviation

P: Probability

* Indicate significance in mean $(P \leq 0.05)$

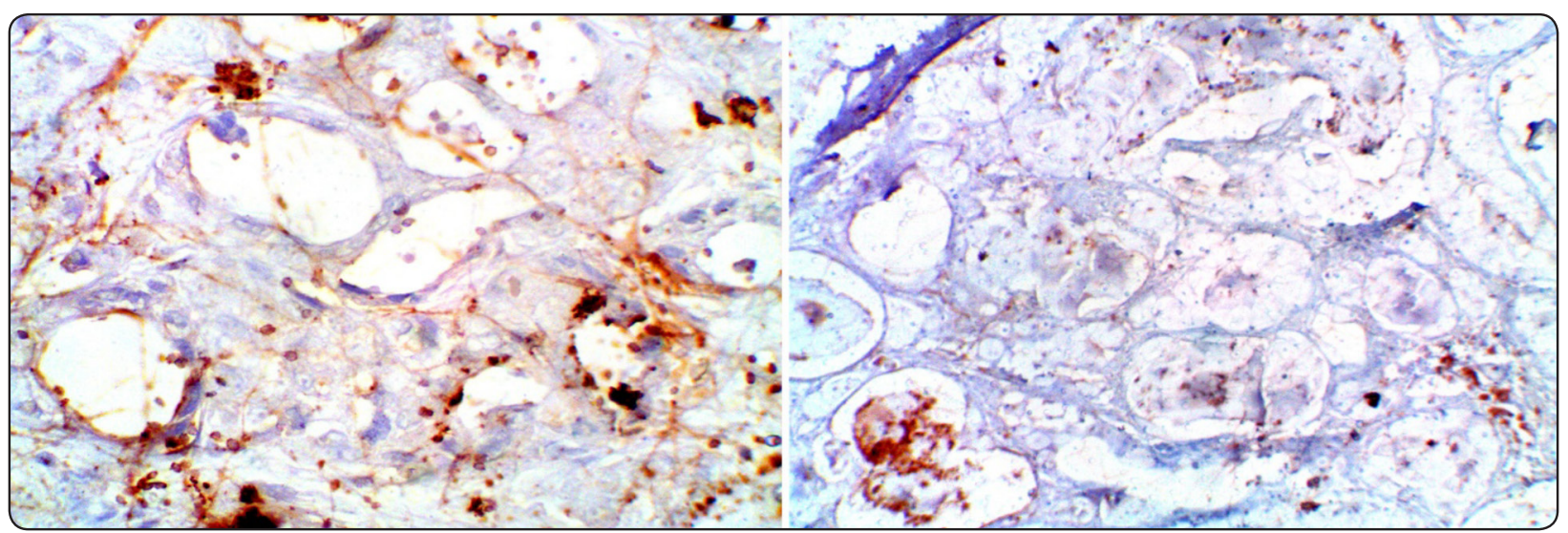

Fig. (6): Photomicrograph revealed low cytoplasmic expression of p-Src in low-grade mucoepidermoid carcinoma with numerous cystic spaces and mucous cells. (x 200) 


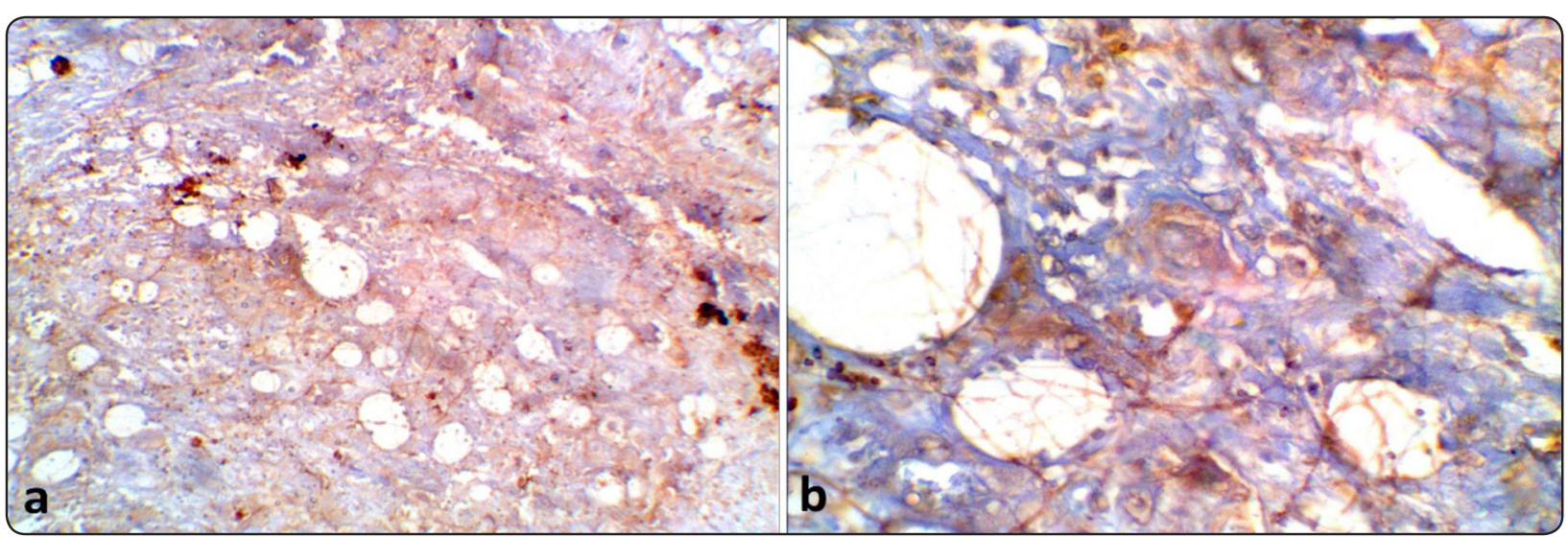

Fig. (7): Photomicrograph of p-Src expression in high-grade mucoepidermoid carcinoma revealed (a) high cytoplasmic and membranous immunoreaction (b) Higher magnification of the previous section. (x 100 and x 400 respectively).

TABLE (VI): p-Src expression concerning DFS:

\begin{tabular}{|c|c|c|c|c|}
\hline \multirow[t]{3}{*}{$\mathrm{p}-\mathrm{Src}$} & \multicolumn{4}{|c|}{ Mean $^{\mathrm{a}}$} \\
\hline & \multirow[t]{2}{*}{ Estimate } & \multirow[t]{2}{*}{ Std. Error } & \multicolumn{2}{|c|}{ 95\% Confidence Interval } \\
\hline & & & Lower Bound & Upper Bound \\
\hline negative expression & 53.604 & 3.278 & 47.179 & 60.029 \\
\hline low expression & 45.667 & 1.778 & 42.182 & 49.151 \\
\hline high expression & 27.540 & 2.579 & 22.486 & 32.594 \\
\hline \multirow[t]{2}{*}{ Overall } & 45.919 & 3.052 & 39.936 & 51.901 \\
\hline & & & Chi-Square & $\mathrm{P}$ \\
\hline \multirow{3}{*}{$\begin{array}{l}\text { Log Rank (Mantel- } \\
\text { Cox) }\end{array}$} & \multicolumn{2}{|c|}{ negative expression \& low expression } & .135 & .714 \\
\hline & \multicolumn{2}{|c|}{ negative expression \& high expression } & 9.713 & $.002 *$ \\
\hline & \multicolumn{2}{|c|}{ low expression \& high expression } & 12.629 & $<0.001 *$ \\
\hline
\end{tabular}

P: Probability *: significance $\leq 0.05$

TABLE (VII): p-Src expression concerning OS:

\begin{tabular}{llll}
\hline & & Chi-Square & P \\
\hline \multirow{2}{*}{ Log Rank (Mantel-Cox) } & negative expression \& low expression & 1.667 & .197 \\
\cline { 2 - 4 } & negative expression \& high expression & 8.066 & $.005^{*}$ \\
\cline { 2 - 4 } & low expression \& high expression & 4.777 & $.029 *$ \\
\hline
\end{tabular}

P: Probability *: significance $\leq 0.05$ 


\section{GLUT-1 and p-Src correlations}

There was a statistically significant correlation between GLUT-1 and p-Src expression regarding tumor grades, living and dead status of the cases, recurrence, DFS, and OS (Table VIII), as well as between both markers' expressions in the studied cases (Table IX).

TABLE (VIII): Correlation of GLUT-1 \& p-Src expression and clinicopathological parameters of the studied cases:

\begin{tabular}{|c|c|c|c|}
\hline & & Glut 1 & $\mathrm{p}-\mathrm{Src}$ \\
\hline \multirow{2}{*}{ Age } & $\mathrm{r}$ & .091 & .059 \\
\hline & $\mathrm{P}$ & .634 & .757 \\
\hline \multirow{2}{*}{ Gender } & $\mathrm{r}$ & .045 & .160 \\
\hline & $\mathrm{P}$ & .813 & .399 \\
\hline \multirow{2}{*}{ Site } & $\mathrm{r}$ & .215 & .323 \\
\hline & $\mathrm{P}$ & .255 & .082 \\
\hline \multirow{2}{*}{ MEC grade } & $\mathrm{r}$ & .709 & .779 \\
\hline & $\mathrm{P}$ & $<0.001 *$ & $<0.001 *$ \\
\hline \multirow{2}{*}{ Alive/ dead } & $\mathrm{r}$ & .247 & .406 \\
\hline & $\mathrm{P}$ & .189 & $.026^{*}$ \\
\hline \multirow{2}{*}{ Recurrence } & $\mathrm{r}$ & .377 & .369 \\
\hline & $\mathrm{P}$ & $.040 *$ & $.045^{*}$ \\
\hline \multirow{2}{*}{ DFS } & $\mathrm{r}$ & -.815 & -.725 \\
\hline & $\mathrm{P}$ & $<0.001^{*}$ & $<0.001 *$ \\
\hline \multirow{2}{*}{ OS } & $\mathrm{r}$ & -.730 & -.540 \\
\hline & $\mathrm{P}$ & $<0.001^{*}$ & $.002 *$ \\
\hline
\end{tabular}

r: Spearman's correlation coefficient

P: Probability *: significance $\leq 0.05$

\section{DISCUSSION}

Neoplastic cells have several characteristics that enable them to maintain higher metabolic activity. To proliferate and survive, malignant cells require energy provided by glucose ${ }^{[38,39]}$. This elevated need for glucose is supplied by a specific group of transport molecules known as GLUTs, which transfer glucose into neoplastic cells ${ }^{[40]}$. GLUTs are maintained in specialized endosomes in cells, and when activated, they become an integral protein plasma membrane, allowing glucose uptake to begin. Hormones and metabolic signals regulate them ${ }^{[41,42]}$, and GLUT-1 is the most well-studied transport molecule in this family, which shows a higher expression in neoplastic cells. Malignant cells have a greater GLUT-1 expression level, which explains their increased glucose consumption to enhance tumor growth ${ }^{[43-46]}$.

The role of the proto-oncogene Src and its family of kinases has been elucidated over many years; it interacts with different receptor tyrosine kinases and participates in various cellular pathways to regulate cell differentiation, adhesion, migration, proliferation, invasion, and angiogenesis, as well as chemoresistance $^{[47-50]}$.

Thirty MEC cases were included in the current study. The immunohistochemical markers GLUT1 and $\mathrm{p}$-Src were assessed in different pathological grades. In 20 cases, GLUT-1 expression was found to be positive $(67 \%)$ This was in line with Demasi et

TABLE (IX): Correlation of both markers' expressions in the studied cases:

\begin{tabular}{|c|c|c|c|c|c|c|c|c|}
\hline & & \multicolumn{6}{|c|}{ Glut 1} & \multirow{3}{*}{$\mathrm{P}$} \\
\hline & & \multicolumn{2}{|c|}{ negative expression } & \multicolumn{2}{|c|}{ low expression } & \multicolumn{2}{|c|}{ high expression } & \\
\hline & & No & $\%$ & No & $\%$ & No & $\%$ & \\
\hline \multirow{3}{*}{ p-src } & negative expression & 7 & $70.0 \%$ & 2 & $18.2 \%$ & 0 & $0.0 \%$ & \multirow{3}{*}{$<0.001 *$} \\
\hline & low expression & 3 & $30.0 \%$ & 7 & $63.6 \%$ & 0 & $0.0 \%$ & \\
\hline & high expression & 0 & $0.0 \%$ & 2 & $18.2 \%$ & 9 & $100.0 \%$ & \\
\hline
\end{tabular}

P: Probability *: significance $\leq \mathbf{0 . 0 5}$ 
al $2010^{[31]}$, who observed positive immunoreaction in more than half of their cases; however, Pereira et al $2016^{[51]}$, Kato et al $2007^{[52]}$, and Ayala et al $2010{ }^{[53]}$ reported GLUT-1 positivity in $90-95 \%$ of OSCC cases. Higher GLUT-1 expression is linked to elevated glucose utilization in tumor cells with increased cellular metabolism, as well as some normal tissues such as erythrocytes, endothelial cells in cerebral arteries, and fetal cells, according to Kato et al $2007^{[52]}$.

According to Haber et al $1998^{[54]}$, Kato et al 2007 ${ }^{[52]}$, and Ayala et al $2010{ }^{[53]}$, GLUT-1's cytoplasmic and membranous expression in the current study may support its function of facilitating and maintaining glycolysis in the cells. Furthermore, when stimulated by cellular differentiation, division, nutritional deficiency, hypoxia, and malignant transformation, Sánchez-Romero et al $2016{ }^{\text {[55] }}$ reported that cytoplasmic expression of GLUT-1 represents enhanced glucose transport. There will be a receptor unmasking at the cell membrane level after induction. When demand rises, GLUT1 is translocated from the cytoplasm to the cell membrane. More GLUT-1 messenger ribonucleic acid is synthesized to match the requirement, and cytoplasmic GLUT-1 concentration rises; this explains why GLUT-1 has a higher cytoplasmic and membranous expression ${ }^{[5]}$.

GLUT-1 in the present study was found to be observed in salivary tissue adjacent to tumor cells, this could be because this tissue was exposed to the same carcinogenic conditions (field cancerization), as the tumor cells, making it at risk of malignant transformation. However, normal salivary tissue used as a control showed no Glute- 1 expression, which could explain why these cells could still rely on predomination on oxidative phosphorylation for energy supply and no need for excess energy by glycolysis.

P-Src was expressed in the cytoplasm and cell membrane of tumor cells in the present study. This agreed with Yeatman et al $2004{ }^{[47]}$, Lieu \& Kopetz
$201{ }^{[50]}$, and $\mathrm{Hu}$ et al $2015^{[56]}$, who reported that $\mathrm{SRC}$ is a proto-oncogene encoding for the tyrosine kinase that is found in the cell membrane as well as the cytoplasm. There have been a few studies that have described the role of p-Src in salivary gland cancers. Src activation in salivary gland tumors is regulated by CCR7 (chemokine receptor 7) and CCL19 (chemokine specific ligand 19); according

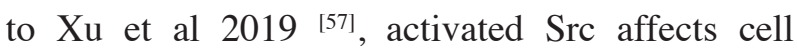
adhesion and cytoskeleton, resulting in increasing the ability of the salivary gland tumor cells to invade and migrate.

The current study reported that high-grade MECs showed higher GLUT-1 expression than intermediate and low-grade MECs; the difference in expression was statistically significant. This was consistent with Gillies \& Gatenby $2007{ }^{[58]}$, as their findings suggested that in MEC, some intermediate-grade tumor cells and all high-grade cells have a lot of energy, so there was a lot of need for increased glycolysis to compensate for this. Furthermore, Gatenby \& Gillies $2008^{[59]}$ discovered that enhanced glycolysis resulted in increased acidosis, which encouraged tumor cell invasion, degradation of extracellular matrix, and promotes angiogenesis. On the other hand, low-grade tumors do not experience the same environmental changes as higher-grade tumors; therefore, their cells continue to rely on oxidative phosphorylation for energy. This was following Costa et al $2008^{[60]}$ and Miles \& Williams $2008^{[61]}$, where they reported lower micro vessel density in high-grade MEC compared to low-grade MEC, indicating hypoxic stimulation to promote glycolysis.

In the present study, GLUT-1 expression in low and intermediate grades was observed to be in focused areas and uneven pattern, which agreed with Gatenby \& Gillies $2008^{\text {[59] }}$, who explained this condition as irregular glycolysis has been linked to cyclic hypoxia, as cells that are hypoxic at one time may no longer be hypoxic minutes later ${ }^{[62,63]}$. 
In the current investigation, increased $\mathrm{p}$-Src expression was statistically significantly correlated with tumor grades, which was consistent with Park et al $1993^{[64]}$ and Cartwright et al $1994^{[65]}$ who reported that Src kinases were downregulated in completely differentiated cells in colon cancer. Although Weber

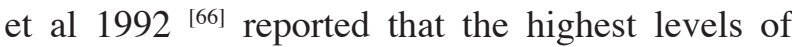
Src activity in human colon tumors occurred in moderately to well-differentiated tumors, and the levels appear to be normal in poorly differentiated colon tumors, the interpretation for this is that poorly differentiated tumors are biologically more aggressive than well-differentiated tumors.

Increased p-src expression was linked to illness relapse in the current study, which was consistent with previous research in HNSCC, Yang et al $2004{ }^{[67]}$ and Johnson et al $2005^{[68]}$; increased GLUT-1 and Src activity is thought to operate as an integrator of divergent signal transduction pathways, enhancing a variety of tumor-promoting actions such as carcinogenesis, invasion, and metastasis. Moreover, Src is frequently hyperactivated in cancer cells, facilitating tumor progression to metastasis by promoting epithelial to mesenchymal transition (EMT) ${ }^{[69]}$, as well as Src signaling has been shown to regulate E-cadherin-associated EMT in pancreatic cancer cells ${ }^{[70]}$.

Higher p-Src expression was linked to DFS and OS in the current study, which was consistent with previous research in breast and cervical cancer ${ }^{[71,72]}$. Other researchers investigated the involvement of SRC in cancers as cervical cancer, breast cancer, and liver cancer, reported that high SRC expression was linked to positive nodal status, reduced DFS, and overall survival (OS) in these various tumor types ${ }^{[72-74]}$. Moreover, SRC expression was linked to prolonged DFS and OS in patients with squamous cell carcinoma of the tongue ${ }^{[75]}$. Higher levels of $\mathrm{p}$-Src were related to shorter relapse-free survival in patients with hepatic metastasized colorectal cancer ${ }^{[76]}$.

\section{CONCLUSION}

GLUT-1 and p-Src might serve as good prognostic markers for MEC as their expression is highly correlated with tumor grades, DFS and OS, therefore, the histopathologic grading is not the only method of detecting the aggressiveness of the MEC, in addition, a necessity for long term followup is recommended. GLUT-1 and p-Src might be considered promising therapeutic targets for MEC. More research is needed to verify if normally apparent salivary gland tissue adjacent to tumor cells is at risk of malignant transformations.

\section{REFERENCES}

1. Pinkston JA and Cole P. Incidence rates of salivary gland tumors: results from a population-based study. Otolaryngol Head Neck Surg., Jun;120(6):834-40, 1999.

2. Torre LA, Bray F, Siegel RL, Ferlay J, Lortet-Tieulent J and Jemal A. Global cancer statistics, 2012. CA Cancer J Clin., Mar;65(2):87-108, 2015.

3. Suh JD and Cho JH. Trends in Head and Neck Cancer in South Korea Between 1999 and 2012. Clin Exp Otorhinolaryngol., Sep;9(3):263-9, 2016.

4. Eveson JW, Auclair P, Gnepp DR and El-Naggar AK. Tumors of the salivary glands. In: Leon B, Eveson JW, Reichart P and Sidransky D, editors. World health organization classification of tumors pathology \& genetics - head and neck tumors. 3rd ed. Lyon, France: IARC Press., 209-81, 2005.

5. Seethala RR and Stenman G. Update from the 4th Edition of the World Health Organization Classification of Head and Neck Tumors: Tumors of the Salivary Gland. Head Neck Pathol., Mar; 11(1):55-67, 2017.

6. Birkeland AC, Foltin SK, Michmerhuizen NL, Hoesli RC, Rosko AJ, Byrd S, Yanik M, Nor JE, Bradford CR, Prince ME, Carey TE, McHugh JB, Spector ME and Brenner JC. Correlation of Crtc1/3-Maml2 fusion status, grade and survival in mucoepidermoid carcinoma. Oral Oncol., May; 68:5-8, 2017.

7. Ellis MA, Graboyes EM, Day TA and Neskey DM. Prognostic factors and occult nodal disease in mucoepidermoid carcinoma of the oral cavity and oropharynx: An analysis of the National Cancer Database. Oral Oncol., Sep; 72:174-178, 2017.

8. Jayasooriya, PR, Karunathilake PR, Siriwardena BS, Amaratunga EA and Attygalla AM. Comparison of grading 
systems of mucoepidermoid carcinoma and the impact on patient survival. Journal of Diagnostic Pathology., 7(1): 42-49, 2013.

9. Tekade SA, Chaudhary MS, Gawande MN and Bagri K. Correlation between mucoepidermoid carcinoma grade and AgNOR count. J Oral Sci., Jun;52(2):275-9, 2010.

10. Janjua OS, Qureshi SM, Khan TS and Alamgir W. Bcl2 protein expression in mucoepidermoid carcinoma of salivary glands: a single institution experience. Hematol Oncol Stem Cell Ther., 5(2):96-100, 2012.

11. Kamal NM, Salem HM and Dahmoush HM. Immunohistochemical expression of epithelial cell adhesion molecule (EpCAM) in mucoepidermoid carcinoma compared to normal salivary gland tissues. Arch Oral Biol., Jul; 79:87-94, 2017.

12. Goode RK and El-Naggar AK. Mucoepidermoid carcinoma (Head and Neck). In Barnes L, Eveson JW, Reichart P, Sidransky D, Pathology and genetics of Head and Neck Tumors. World Health Organization Classification of Tumors. Lyon: IARC Press., 219-220, 2005.

13. Barnes L. Surgical Pathology of the Head and Neck 3rd edition. Informa Healthcare USA, Inc. New York, 2009.

14. Spiro RH, Huvos AG, Berk $R$ and Strong EW. Mucoepidermoid carcinoma of salivary gland origin. A clinicopathologic study of 367 cases. Am J Surg., Oct; 136(4):461-8, 1978.

15. Brandwein MS, Ivanov K, Wallace DI, Hille JJ, Wang B, Fahmy A, Bodian C, Urken ML, Gnepp DR, Huvos A, Lumerman H and Mills SE. Mucoepidermoid carcinoma: a clinicopathologic study of 80 patients with special reference to histological grading. Am J Surg Pathol., Jul; 25(7):835-45, 2001.

16. Byrd SA, Spector ME, Carey TE, Bradford CR and $\mathrm{McHugh}$ JB. Predictors of recurrence and survival for head and neck mucoepidermoid carcinoma. Otolaryngol Head Neck Surg., Sep;149(3):402-8, 2013.

17. Retzbach EP, Sheehan SA, Nevel EM, Batra A, Phi T, Nguyen ATP, Kato Y, Baredes S, Fatahzadeh M, Shienbaum $\mathrm{AJ}$ and Goldberg GS. Podoplanin emerges as a functionally relevant oral cancer biomarker and therapeutic target. Oral Oncol., Mar; 78:126-136, 2018.

18. de Souza LB, de Oliveira LC, Nonaka CFW, Lopes MLDS, Pinto LP and Queiroz LMG. Immunoexpression of GLUT1 and angiogenic index in pleomorphic adenomas, adenoid cystic carcinomas, and mucoepidermoid carcinomas of the salivary glands. Eur Arch Otorhinolaryngol., Jun; 274(6):2549-2556, 2017.

19. Vander Heiden MG, Cantley LC and Thompson CB.
Understanding the Warburg effect: the metabolic requirements of cell proliferation. Science., May 22; 324(5930): 1029-33, 2009.

20. Cantor JR and Sabatini DM. Cancer cell metabolism: one hallmark, many faces. Cancer Discov., Oct;2(10):881-98, 2012.

21. Teoh ST and Lunt SY. Metabolism in cancer metastasis: bioenergetics, biosynthesis, and beyond. Wiley Interdiscip Rev Syst Biol Med., Mar;10(2), 2018.

22. Reitman ZJ and Yan H. Isocitrate dehydrogenase 1 and 2 mutations in cancer: alterations at a crossroads of cellular metabolism. J Natl Cancer Inst., Jul 7;102(13):932-41, 2010 .

23. Mori Y, Tsukinoki K, Yasuda M, Miyazawa M, Kaneko A and Watanabe Y. Glucose transporter type 1 expression are associated with poor prognosis in patients with salivary gland tumors. Oral Oncol., Jul;43(6):563-9, 2007.

24. Thorens B and Mueckler M. Glucose transporters in the 21st Century. Am J Physiol Endocrinol Metab., Feb;298(2): E141-5, 2010.

25. Oh S, Kim H, Nam K and Shin I. Glut1 promotes cell proliferation, migration and invasion by regulating epidermal growth factor receptor and integrin signaling in triple-negative breast cancer cells. BMB Rep., Mar; 50(3):132-137, 2017

26. Busk M, Horsman MR, Kristjansen PE, van der Kogel AJ, Bussink J and Overgaard J. Aerobic glycolysis in cancers: implications for the usability of oxygen-responsive genes and fluorodeoxyglucose-PET as markers of tissue hypoxia. Int J Cancer., Jun 15;122(12):2726-34, 2008.

27. Ortega AD, Sánchez-Aragó M, Giner-Sánchez D, SánchezCenizo L, Willers I and Cuezva JM. Glucose avidity of carcinomas. Cancer Lett., Apr 18;276(2):125-35, 2009.

28. Yu M, Yongzhi H, Chen S, Luo X, Lin Y, Zhou Y, Jin H, Hou B, Deng Y, Tu L and Jian Z. The prognostic value of GLUT1 in cancers: a systematic review and meta-analysis. Oncotarget., Jun 27;8(26):43356-43367, 2017.

29. Liao H, Wang Z, Deng Z, Ren H and Li X. Curcumin inhibits lung cancer invasion and metastasis by attenuating GLUT1/MT1-MMP/MMP2 pathway. Int J Clin Exp Med., Jun 15;8(6):8948-57, 2015.

30. Nagarajan A, Dogra SK, Sun L, Gandotra N, Ho T, Cai G, Cline G, Kumar P, Cowles RA and Wajapeyee N. Paraoxonase 2 Facilitates Pancreatic Cancer Growth and Metastasis by Stimulating GLUT1-Mediated Glucose Transport. Mol Cell., Aug 17;67(4):685-701.e6, 2017. 
31. Demasi AP, Costa AF, Altemani A, Furuse C, Araújo NS and Araújo VC. Glucose transporter protein 1 expression in mucoepidermoid carcinoma of salivary gland: correlation with grade of malignancy. Int J Exp Pathol., Apr;91(2):107-13, 2010.

32. Martínez-Pérez J, Lopez-Calderero I, Saez C, Benavent M, Limon ML, Gonzalez-Exposito R, Soldevilla B, RiescoMartínez MC, Salamanca J, Carnero A and Garcia-Carbonero R. Prognostic relevance of Src activation in stage II-III colon cancer. Hum Pathol., Sep; 67:119-125, 2017.

33. Hu C, Deng Z, Zhang Y, Yan L, Cai L, Lei J and Xie Y. The prognostic significance of Src and $\mathrm{p}$-Src expression in patients with osteosarcoma. Med Sci Monit., Feb 28; 21:638-45, 2015 .

34. Defilippi P, Di Stefano P and Cabodi S. p130Cas: a versatile scaffold in signaling networks. Trends Cell Biol., May;16(5):257-63, 2006.

35. Humar B, Fukuzawa R, Blair V, Dunbier A, More H, Charlton A, Yang HK, Kim WH, Reeve AE, Martin I and Guilford P. Destabilized adhesion in the gastric proliferative zone and $\mathrm{c}$-Src kinase activation mark the development of early diffuse gastric cancer. Cancer Res., Mar 15;67(6):2480-9, 2007.

36. Choi CW, Kim YH, Sohn JH, Lee H and Kim WS. Focal adhesion kinase and Src expression in premalignant and malignant skin lesions. Exp Dermatol., May;24(5):361-4, 2015.

37. Sandilands E, Schoenherr C and Frame MC. p70S6K is regulated by focal adhesion kinase and is required for Src-selective autophagy. Cell Signal., Sep;27(9):1816-23, 2015.

38. Pires FR, de Almeida OP, de Araújo VC and Kowalski LP. Prognostic factors in head and neck mucoepidermoid carcinoma. Arch Otolaryngol Head Neck Surg., Feb;130(2):174-80, 2004.

39. Carvalho KC, Cunha IW, Rocha RM, Ayala FR, Cajaíba MM, Begnami MD, Vilela RS, Paiva GR, Andrade RG and Soares FA. GLUT1 expression in malignant tumors and its use as an immunodiagnostic marker. Clinics (Sao Paulo)., 66(6):965-72, 2011.

40. Wood IS and Trayhurn P. Glucose transporters (GLUT and SGLT): expanded families of sugar transport proteins. Br J Nutr., Jan;89(1):3-9, 2003.

41. Zhao FQ and Keating AF. Functional properties and genomics of glucose transporters. Curr Genomics., Apr;8(2):113-28, 2007.
42. Eckert AW, Lautner MH, Schütze A, Taubert H, Schubert $\mathrm{J}$ and Bilkenroth $\mathrm{U}$. Coexpression of hypoxia-inducible factor- $1 \alpha$ and glucose transporter- 1 is associated with poor prognosis in oral squamous cell carcinoma patients. Histopathology., Jun;58(7):1136-47, 2011.

43. Smith TA. Facilitative glucose transporter expression in human cancer tissue. Br J Biomed Sci., 56(4):285-92, 1999.

44. Ayala FR, Rocha RM, Carvalho KC, Carvalho AL, da Cunha IW, Lourenço SV and Soares FA. GLUT1 and GLUT3 as potential prognostic markers for Oral Squamous Cell Carcinoma. Molecules., Apr 1;15(4):2374-87, 2010.

45. Salla JT, Johann AC, Lana AM, do Carmo MA, Nunes FD and Mesquita RA. Immunohistochemical study of GLUT-1 in oral peripheral nerve sheath tumors. Oral Dis., Sep;14(6):510-3, 2008.

46. Parente P, Coli A, Massi G, Mangoni A, Fabrizi MM and Bigotti G. Immunohistochemical expression of the glucose transporters Glut-1 and Glut-3 in human malignant melanomas and benign melanocytic lesions. J Exp Clin Cancer Res., Sep 2;27(1):34, 2008.

47. Yeatman TJ. A renaissance for SRC. Nat Rev Cancer., Jun;4(6):470-80, 2004.

48. Irby RB and Yeatman TJ. Role of Src expression and activation in human cancer. Oncogene., Nov 20; 19(49):5636-42, 2000.

49. Taylor SJ and Shalloway D. Src and the control of cell division. Bioessays., Jan;18(1):9-11, 1996.

50. Lieu C and Kopetz S. The SRC family of protein tyrosine kinases: a new and promising target for colorectal cancer therapy. Clin Colorectal Cancer., Apr;9(2):89-94, 2010.

51. Pereira KM, Feitosa SG, Lima AT, Luna EC, Cavalcante RB, de Lima KC, Chaves FN and Costa FW. Immunohistochemical Evaluation of Glucose Transporter Type 1 in Epithelial Dysplasia and Oral Squamous Cell Carcinoma. Asian Pac J Cancer Prev., 17(1):147-51, 2016.

52. Kato Y, Tsuta K, Seki K, Maeshima AM, Watanabe S, Suzuki K, Asamura H, Tsuchiya R and Matsuno Y. Immunohistochemical detection of GLUT-1 can discriminate between reactive mesothelium and malignant mesothelioma. Mod Pathol., Feb;20(2):215-20, 2007.

53. Ayala FR, Rocha RM, Carvalho KC, Carvalho AL, da Cunha IW, Lourenço SV and Soares FA. GLUT1 and GLUT3 as potential prognostic markers for Oral Squamous Cell Carcinoma. Molecules., Apr 1;15(4):2374-87, 2010.

54. Haber RS, Rathan A, Weiser KR, Pritsker A, Itzkowitz SH, Bodian C, Slater G, Weiss A and Burstein DE. GLUT1 
glucose transporter expression in colorectal carcinoma: a marker for poor prognosis. Cancer., Jul 1;83(1):34-40, 1998.

55. Sánchez-Romero C, Bologna-Molina R, MosquedaTaylor A and Paes de Almeida O. Immunohistochemical Expression of GLUT-1 and HIF- $1 \alpha$ in Tooth Germ, Ameloblastoma, and Ameloblastic Carcinoma. Int J Surg Pathol., Aug;24(5):410-8, 2016.

56. Hu C, Deng Z, Zhang Y, Yan L, Cai L, Lei J and Xie Y. The prognostic significance of Src and p-Src expression in patients with osteosarcoma. Med Sci Monit., Feb 28; 21:638-45, 2015.

57. Xu H, Yang X, Zhang Q and Chen L. Effects of CCR7 and Src on invasion and migration of salivary gland tumor. Eur Rev Med Pharmacol Sci., May;23(9):3813-3820, 2019.

58. Gillies RJ and Gatenby RA. Adaptive landscapes and emergent phenotypes: why do cancers have high glycolysis? J Bioenerg Biomembr., Jun;39(3):251-7, 2007.

59. Gatenby RA and Gillies RJ. A microenvironmental model of carcinogenesis. Nat Rev Cancer., Jan;8(1):56-61, 2008.

60. Costa AF, Demasi AP, Bonfitto VL, Bonfitto JF, Furuse C, Araújo VC, Metze K and Altemani A. Angiogenesis in salivary carcinomas with and without myoepithelial differentiation. Virchows Arch., Oct;453(4):359-67, 2008.

61. Miles KA and Williams RE. Warburg revisited: imaging tumor blood flow and metabolism. Cancer Imaging., Mar 25;8(1):81-6, 2008 .

62. Dewhirst MW, Cao Y and Moeller B. Cycling hypoxia and free radicals regulate angiogenesis and radiotherapy response. Nat Rev Cancer., Jun;8(6):425-37, 2008.

63. Airley RE and Mobasheri A. Hypoxic regulation of glucose transport, anaerobic metabolism and angiogenesis in cancer: novel pathways and targets for anticancer therapeutics. Chemotherapy., 53(4):233-56, 2007.

64. Park J, Meisler AI and Cartwright CA. c-Yes tyrosine kinase activity in human colon carcinoma. Oncogene., Oct;8(10):2627-35, 1993.

65. Cartwright CA, Coad CA and Egbert BM. Elevated c-Src tyrosine kinase activity in premalignant epithelia of ulcerative colitis. J Clin Invest., Feb;93(2):509-15, 1994.

66. Weber TK, Steele G and Summerhayes IC. Differential pp60c-src activity in well and poorly differentiated human colon carcinomas and cell lines. J Clin Invest., Sep;90(3):815-21, 1992.

67. Yang Z, Bagheri-Yarmand R, Wang RA, Adam L, Papadimitrakopoulou VV, Clayman GL, El-Naggar
A, Lotan R, Barnes CJ, Hong WK and Kumar R. The epidermal growth factor receptor tyrosine kinase inhibitor ZD1839 (Iressa) suppresses c-Src and Pak1 pathways and invasiveness of human cancer cells. Clin Cancer Res., Jan 15;10(2):658-67, 2004.

68. Johnson FM, Saigal B, Talpaz M and Donato NJ. Dasatinib (BMS-354825) tyrosine kinase inhibitor suppresses invasion and induces cell cycle arrest and apoptosis of head and neck squamous cell carcinoma and non-small cell lung cancer cells. Clin Cancer Res., Oct 1;11(19 Pt 1):6924-32, 2005.

69. Summy JM and Gallick GE. Src family kinases in tumor progression and metastasis. Cancer Metastasis Rev., Dec;22(4):337-58, 2003.

70. Nagathihalli NS and Merchant NB. Src-mediated regulation of E-cadherin and EMT in pancreatic cancer. Front Biosci (Landmark Ed)., Jun 1; 17:2059-69, 2012.

71. Elsberger B, Fullerton R, Zino S, Jordan F, Mitchell TJ, Brunton VG, Mallon EA, Shiels PG and Edwards J. Breast cancer patients' clinical outcome measures are associated with Src kinase family member expression. Br J Cancer., Sep 7;103(6):899-909, 2010.

72. Hou T, Xiao J, Zhang H, Gu H, Feng Y and Li J. Phosphorylated c-Src is a novel predictor for recurrence in cervical squamous cell cancer patients. Int J Clin Exp Pathol., May 15;6(6):1121-7, 2013.

73. Zhang L, Teng Y, Zhang Y, Liu J, Xu L, Qu J, Hou K, Yang $\mathrm{X}$, Liu Y and Qu X. c-Src expression is predictive of poor prognosis in breast cancer patients with bone metastasis, but not in patients with visceral metastasis. APMIS., Jul;120(7):549-57, 2012.

74. Chen ML, Chai CY, Yeh KT, Wang SN, Tsai CJ, Yeh YT and Yang SF. Crosstalk between activated and inactivated c-Src in hepatocellular carcinoma. Dis Markers., 30(6):325-33, 2011

75. Theocharis S, Klijanienko J, Giaginis C, Alexandrou P, Patsouris E and Sastre-Garau X. FAK and Src expression in mobile tongue squamous cell carcinoma: associations with clinicopathological parameters and patients survival. J Cancer Res Clin Oncol., Aug;138(8):1369-77, 2012.

76. Kopetz S, Morris VK, Parikh N, Overman MJ, Jiang ZQ, Maru D, Elvin P and Gallick G. Src activity is modulated by oxaliplatin and correlates with outcomes after hepatectomy for metastatic colorectal cancer. BMC Cancer., Sep 10; 14:660, 2014. 